\title{
Addendum
}

\section{Whole-genome sequencing for neonatal intensive care unit outbreak investigations: Insights and lessons learned - ADDENDUM}

\author{
Sarah E. Sansom, Latania K. Logan, Stefan J. Green, Nicholas M. Moore and Mary K. Hayden
}

DOI: https://doi.org/10.1017/ash.2021.161. Published online by Cambridge University Press: 24 June 2021

In the above article ${ }^{1}$, WGS Lesson \#3 was originally omitted; it reads:

WGS Lesson \#3: WGS provides high resolution for strain typing in outbreak investigations and can provide support for transmission clusters that would have otherwise been miscategorized

\section{Reference}

Sansom, S., Logan, L., Green, S., Moore, N., \& Hayden, M. (2021). Whole-genome sequencing for neonatal intensive care unit outbreak investigations: Insights and lessons learned. Antimicrobial Stewardship \& Healthcare Epidemiology, 1(1), E2. doi: 10.1017/ash.2021.161

Cite this article: Sansom SE, et al. (2021). Whole-genome sequencing for neonatal intensive care unit outbreak investigations: Insights and lessons learned - ADDENDUM. Antimicrobial Stewardship \& Healthcare Epidemiology, https://doi.org/10.1017/ash.2021.182

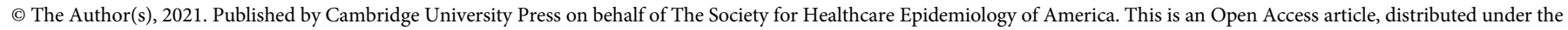

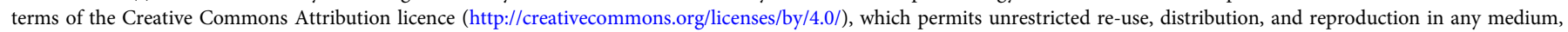
provided the original work is properly cited. 